\title{
Metabolic characteristics of the deltoid muscle in patients with chronic obstructive pulmonary disease
}

\author{
J.G. Gea*, M. Pasto*, M.A. Carmona*, M. Orozco-Levi*, J. Palomeque", J. Broquetas*
}

\begin{abstract}
Metabolic characteristics of the deltoid muscle in patients with chronic obstructive pulmonary disease. J.G. Gea, M. Pasto, M.A. Carmona, M. Orozco-Levi, J. Palomeque, J. Broquetas. (C) ERS Journals Ltd 2001.

ABSTRACT: The purpose of this study was to analyse key enzyme activities of the deltoid muscle (DM) in chronic obstructive pulmonary disease (COPD) patients.

The activities of one oxidative enzyme (citrate synthase (CS)), two glycolytic enzymes (lacatate dehydrogenase (LD); and phosphofructokinase (PFK)) and one enzyme related to the use of energy stores (creatine kinase $(\mathrm{CK})$ ) were determined in the DM of 10 patients with COPD and nine controls. Exercise capacity (cycloergometry) and the handgrip strength were also evaluated.

Although exercise capacity was markedly reduced in COPD $(57+20 \%$ predicted $)$, their handgrip strength was relatively preserved $(77 \pm 19 \%$ pred). The activity of $L D$ was higher in the COPD patients $\left(263.9 \pm 68.2\right.$ versus $184.4 \pm 46.5 \mathrm{mmol} \cdot \mathrm{min}^{-1} \cdot \mathrm{g}^{-1}$, $\mathrm{p}<0.01)$, with a similar trend for CS $\left(67.3 \pm 33.3\right.$ versus $46.0 \pm 17.4 \mathrm{mmol} \cdot \mathrm{min}^{-1} \cdot \mathrm{g}^{-1}$, $\mathbf{p}=0.07)$. Interestingly, the activity of the latter enzyme was significantly higher than controls if only severe COPD patients were considered $\left(81.8 \pm 31.2 \mathrm{mmol} \cdot \mathrm{min}^{-1} \cdot \mathrm{g}^{-1}\right.$, $\mathrm{p}<0.01)$. PFK and CK activities were similar for controls and COPD.

Chronic obstructive patients show a preserved or even increased (severe disease) oxidative capacity in their deltoid muscle. This coexists with a greater capacity in the anaerobic part of the glycolysis. These findings are different to those previously observed in muscles of the lower limbs.

Eur Respir J 2001; 17: 939-945.
\end{abstract}

*Dept of Pneumology, Respiratory and Environmental Research Unit, Hospital del Mar-IMIM, CEXS, Pompeu Fabra University and Autonomous University of Barcelona and ${ }^{\#}$ Dept of Physiology, School of Sciences, University of Barcelona, Barcelona, Spain.

Correspondence: J.G. Gea, Unitat de Recerca Respiratòria I Ambiental, IMIM-Hospital del Mar, E-8003 Barcelona, Spain.

Fax: 34932213237

Keywords: Citrate synthase creatinine kinase

lactate dehydrogenase

lung diseases

peripheral skeletal muscle function

phosphofructokinase

Received: July 52000

Accepted after revision December 12 2000

One of the main symptoms in patients with chronic obstructive pulmonary disease (COPD) is limitation to exercise [1]. This limitation was classically attributed to ventilatory factors, and the role of peripheral skeletal muscle dysfunction has only been recognized in recent years [1-3]. The potential causes of this functional impairment would include loss in muscle mass, fibre atrophy, and decreases in the percentage of oxidative fibres and enzyme activities $[4,5]$. However, it is unclear whether muscle weakness is a generalized problem, or if it only or predominately affects some muscle groups. In addition, the causes of skeletal muscle weakness, and the specific role for each, still remain controversial. However, it is worth noting that most of the previous studies were performed in muscles from the lower limbs, where deconditioning due to reduction in activity may be particularly relevant but could coexist with other factors. The study of muscles from other locations, such as the deltoid muscle (DM), could contribute not only to elucidate whether skeletal muscle changes in COPD are homogeneous, but also to clarify whether systemic or local aetiological factors play the predominant role in inducing such changes. The objectives of the study were, firstly, to evaluate the metabolic capacity of the $\mathrm{DM}$ in COPD patients, and secondly, to investigate the potential relationships between lung function and the activity of different key enzymes in DM.

\begin{abstract}
Methods
\section{Population}

Ten patients with severe-to-mild COPD were included (table 1). The COPD diagnosis was based on smoking history and forced spirometry showing nonreversible airways obstruction. All patients were clinically stable, with absence of exacerbations during the 2 months prior to the study. Recruitment was carried out consecutively on COPD patients who consulted the authors' department and subsequently agreed to participate in the study. In order to avoid bias due to hormonal factors, only males were included. At the same time, individuals with malnutrition (body mass index $(\mathrm{BMI})<20 \mathrm{~kg} \cdot \mathrm{m}^{-2}$ ), alcoholism $\left(>80 \mathrm{~g} \cdot \mathrm{day}^{-1}\right)$, bronchial asthma, associated chronic respiratory failure, neuromuscular or metabolic diseases, undergoing chronic treatment with systemic steroids, systemic $\beta$-agonists, $\mathrm{Ca}^{++}$antagonists or diuretics, and those undergoing rehabilitation were excluded. Nine subjects of similar age and anthropometry, but with normal lung function $\left(60.8 \pm 9.0 \mathrm{yrs}\right.$, BMI $25 \pm 4 \mathrm{~kg} \cdot \mathrm{m}^{-2}$, forced expiratory volume in one second (FEV1) $95.3 \pm 12.6$ ) were also recruited to serve as a control group. The study was approved by the Research Committee on Human
\end{abstract}


Table 1.-Individual and mean values of the main general and functional variables obtained in chronic obstructive pulmonary disease patients

\begin{tabular}{|c|c|c|c|c|c|c|c|c|c|c|c|}
\hline $\begin{array}{l}\text { Patient } \\
\text { No. }\end{array}$ & $\begin{array}{l}\text { Age } \\
\text { yrs }\end{array}$ & $\underset{\mathrm{kg} \cdot \mathrm{m}^{-2}}{\mathrm{BMI}}$ & $\begin{array}{l}\text { FEV1 } \\
\% \text { pred }\end{array}$ & $\underset{\%}{\mathrm{FEV}_{1} / \mathrm{FVC}}$ & $\underset{\%}{\mathrm{RV} / \mathrm{TLC}}$ & $\begin{array}{l}D \mathrm{~L}, \mathrm{CO} \\
\% \text { ref }\end{array}$ & $\begin{array}{c}{\mathrm{Pa}, \mathrm{O}_{2}} \\
\mathrm{mmHg}\end{array}$ & $\begin{array}{l}V_{\mathrm{O}_{2}} \text {,max } \\
\% \text { pred }\end{array}$ & $\begin{array}{l}P \text { I,max } \\
\% \text { pred }\end{array}$ & $\begin{array}{l}P \text { E,max } \\
\% \text { pred }\end{array}$ & $\begin{array}{c}\text { Handgrip } \\
\% \text { pred }\end{array}$ \\
\hline 1 & 53 & 28 & 60 & 62 & 50 & 78 & 83 & 89 & 90 & 77 & 61 \\
\hline 2 & 74 & 24 & 59 & 59 & 53 & 70 & 76 & ND & 131 & 144 & 97 \\
\hline 3 & 52 & 20 & 74 & 59 & 49 & 94 & 89 & 69 & 95 & 83 & 56 \\
\hline 4 & 78 & 22 & 50 & 53 & 68 & 56 & 91 & 33 & 64 & 52 & 73 \\
\hline 5 & 40 & 20 & 62 & 59 & ND & ND & 95 & 40 & 89 & 85 & 81 \\
\hline 6 & 63 & 21 & 50 & 49 & 51 & 55 & 92 & 50 & 62 & 57 & 51 \\
\hline 7 & 67 & 22 & 49 & 55 & 63 & 61 & 84 & 74 & 68 & 58 & 87 \\
\hline 8 & 71 & 30 & 22 & 47 & 69 & 67 & 74 & 53 & 88 & 78 & 112 \\
\hline 9 & 58 & 20 & 35 & 50 & 67 & 38 & 65 & 33 & 25 & ND & 65 \\
\hline 10 & 69 & 23 & 49 & 60 & 69 & 73 & 77 & 68 & 87 & ND & 87 \\
\hline Mean & 63 & 23 & 51 & 55 & 60 & 66 & 83 & 57 & 80 & 79 & 77 \\
\hline$\pm \mathrm{SD}$ & 12 & 3 & 15 & 5 & 9 & 16 & 10 & 20 & 28 & 29 & 19 \\
\hline
\end{tabular}

BMI: body mass index; FEV1: forced expiratory volume in one second; FEV1/FVC: ratio of FEV1 to forced vital capacity; RV/TLC: ratio of residual volume to total lung capacity; $D \mathrm{~L}, \mathrm{CO}$ : carbon monoxide diffusion capacity or the lung; $P$ a, $\mathrm{O}_{2}$; $V_{\mathrm{O}_{2}}$, max: maximal oxygen consumption; PI,max: maximal inspiratory mouth pressure; $P \mathrm{E}$,max: maximal expiratory mouth pressure.

Investigation at the authors' centre, and informed written consent was obtained from each participant.

\section{Study design}

This was a cross-sectional study.

First day. Patients were submitted to a medical questionnaire, and underwent physical examination, nutritional evaluation and conventional lung function testing.

Second day. The strength of respiratory and peripheral muscles was evaluated and subjects performed a conventional exercise test.

Third day. Open biopsies from DM were obtained and subsequently processed.

\section{Lung function tests}

Forced spirometry with bronchodilator response (Datospir 92, Sibel, Barcelona, Spain) as well as intrathoracic gas volume, airways resistance and carbon monoxide diffusing capacity of the lung (Masterlab, Jaeger, Würzburg, Germany) were measured in each individual. Reference values were those for a Mediterranean population [6-8]. Blood samples were obtained from the radial artery and were analysed using standard polarographic techniques (ABL 330, Radiometer, Copenhagen, Denmark).

\section{Respiratory muscle function tests}

Respiratory muscle strength was assessed through maximal inspiratory and expiratory pressures obtained at the mouth $(P \mathrm{I}$,max and $P$ E,max, respectively) using a mouthpiece (Sibelmed-163, Sibel, Barcelona, Spain) connected to a pressure transducer (Transpac II, Abbott, Chicago, IL, USA). Reference values were those reported by WiLSON et al. [9].

\section{Peripheral muscle strength}

The upper limb strength was approximated using a hand dynamometer (Biopac Systems Inc., Santa Barbara, CA, USA). Peak handgrip force (dynes) was measured at the nondominant side, with the elbow in a $90^{\circ}$ flexion, and the underarm and wrist in neutral position. At least three attempts were performed, and the highest value was taken in each case. Data were related to those published by MATHIOWETZ et al. [10].

\section{Exercise capacity}

A maximal incremental exercise test was performed on a cycloergometer (Ergofit 6780, Rheisland, Germany) and the load increased stepwise, 25 Watts every $2 \mathrm{~min}$. Electrocardiagram, transcutaneous oxygen saturation $\left(\mathrm{Sa}_{\mathrm{a}} \mathrm{O}_{2}\right)($ Ohmeda $3700 \mathrm{Biox}$, Chicago, IL, USA) and expired gases were continuously recorded (Oxycon 3.2, Jaeger, Würzburg, Germany).

\section{Muscle biopsy}

Percutaneous biopsies of the nondominant DM were obtained from its central region. Biopsy sites were anaesthetized previously with $2 \%$ lidocaine and $1-1.5 \mathrm{~cm}$ skin incisions were made. Muscle samples were divided into two parts. One was embedded in ornithyl carbamyl transferase (TissueTek, Thousands, Elkhart, IN, USA), frozen in isopentane and cooled in liquid nitrogen for use in fibre-typing procedures. The other was immediately allocated in a tube, frozen and stored at $-70^{\circ} \mathrm{C}$ until needed.

\section{Percentage of different fibre types}

Muscle sections were obtained in a cryostat and type I and II fibres were identified using the standard adenosine triphosphatase stain at different $\mathrm{pHs}$. 
At least 100 fibres were counted and measured in each case (Videoplan-2, Zeiss, Konton Electronics, Bremen, Germany).

\section{Muscle enzyme activity determinations}

Samples were homogenized in a buffer solution (Tris- $\mathrm{HCl} 50 \mathrm{mM}$, ethylenediamine tetraacetic acid (EDTA) $4 \mathrm{mM}$, potassium fluoride $30 \mathrm{mM}$ and 2 - $\beta$-mercaptoetphanol $30 \mathrm{mM})(\mathrm{pH} \mathrm{7.0)}$ using a Teflon/glass homogenizer, held in an ice bath. This was centrifuged and aliquots were used for measuring the activities of phosphofructokinase (PFK) (common part of the glycolytic pathway), lactate dehydrogenase (LD) (anaerobic part of glycolosis), citrate synthase (CS) (citric acid cycle) and creatine kinase (CK) (use of the energy stored in phosphocreatine). These were measured at $25^{\circ} \mathrm{C}$ using the spectrophotometric technique as previously described [11-13]. Each assay was performed in duplicate and the mean is reported. Data are expressed in $\mathrm{mmol} \cdot \mathrm{min}^{-1} \cdot \mathrm{g}^{-1}$ of muscle wet weight.

\section{Statistical analysis}

Data are expressed as mean \pm SD. The MannWhitney test was used to compare the control with either COPD or severe COPD groups. Pearson's coefficient was employed to assess correlations between two different variables and the linear regression analysis was used where appropriate. A value of $p \leq 0.05$ was considered statistically significant.

\section{Results \\ General and functional assessment}

Individual and mean data from the main general and functional variables appear in table 1. Age, height, weight, BMI and protein levels were within normal ranges and similar for COPD and control groups. Patients with COPD had mild-to-severe airways obstruction, associated in most of the cases to air trapping. Although some were hypoxaemic, oxygen tension in arterial blood $\left(\mathrm{Pa}, \mathrm{O}_{2}\right)$ was always above $60 \mathrm{mmHg}$, without hypercapnia. The strength of respiratory muscles was lower in COPD $(P \mathrm{I}, \mathrm{max}$, $79.9 \pm 27.6$ versus $102.1 \pm 20.5 \%$ predicted; and $P$ E, $\max$, $79.2 \pm 29.0$ versus $92.0 \pm 9.7 \%$ pred, $\mathrm{p}<0.05$ each), but $P \mathrm{I}$,max was markedly reduced only in one patient. As expected, exercise tolerance was reduced in COPD (load, 80.6 \pm 30.0 versus $162.5 \pm 41.1$ Watts, $\mathrm{p}<0.01$; maximal oxygen consumption $\left(V_{\mathrm{O}_{2}}\right.$, max $), 57 \pm 20$ versus $85 \pm 12 \%$ pred, $\mathrm{p}=0.01$ ) but interestingly $\mathrm{Sa}_{\mathrm{a}} \mathrm{O}_{2}$ did not decrease significantly $(96.3 \pm 2.7-95.3 \pm 2.2 \%)$. Finally, handgrip strength was relatively preserved $(77 \pm 19 \%$ pred, $87 \pm 29 \%$ pred in our controls).

\section{Structural and metabolic assessment}

Results for fibre size and percentages, as well as for the four enzyme activities, appear in figures $1-3$. Fibre characteristics were similar between controls and COPD (fig. 1). The same was observed when the former were compared with severe COPD. However, there was a trend to increase type I fibres with increased air trapping, although this did not reach statistical significance (with residual volume/total lung capacity $(\mathrm{RV} / \mathrm{TLC}), \mathrm{r}=0.483, \mathrm{p}=0.06)$. With reference to enzyme activities, LD activity was higher in COPD than in controls $(263.9 \pm 68.2$ versus $184.4 \pm$ $46.5 \mathrm{mmol} \cdot \mathrm{min}^{-1} \cdot \mathrm{g}^{-1}, \mathrm{p}<0.01$, respectively) and $\mathrm{a}$ similar trend was observed for CS $(67.3 \pm 33.3$ versus $46.0 \pm 17.4 \mathrm{mmol} \cdot \mathrm{min}^{-1} \cdot \mathrm{g}^{-1}, \mathrm{p}=0.07$ ) (fig. 2). If only those patients with severe COPD (FEV1 $\leq 50 \%$ of reference values, $n=6$ ) were considered, they showed significantly higher activities for both enzymes $\left(296.1 \pm 56.3 \mathrm{mmol} \cdot \mathrm{min}^{-1} \cdot \mathrm{g}^{-1}, \mathrm{p}=0.001\right.$, and $81.8 \pm$ $31.2 \mathrm{mmol} \cdot \mathrm{min}^{-1} \cdot \mathrm{g}^{-1}, \mathrm{p}<0.01$, for LD and CS, respectively) than controls. No significant differences were found for PFK and CK. Interestingly, a significant relationship was observed between oxidative capacity, represented by CS enzyme, and either airways obstruction (with FEV1, $\mathrm{r}=-0.664$ for all subjects, $\mathrm{p}<0.01 ; \mathrm{r}=-0.721$ for COPD only, $\mathrm{p}=0.02$ ) or air trapping (with $\mathrm{RV} / \mathrm{TLC}, \mathrm{r}=0.563$ for ill individuals $\mathrm{p}=0.01 ; \mathrm{r}=0.423$ for COPD only, NS) (fig. 3). A similar phenomenon was observed for LD in the overall population (with $\mathrm{FEV} 1, \mathrm{r}=-0.593, \mathrm{p}<0.01$;
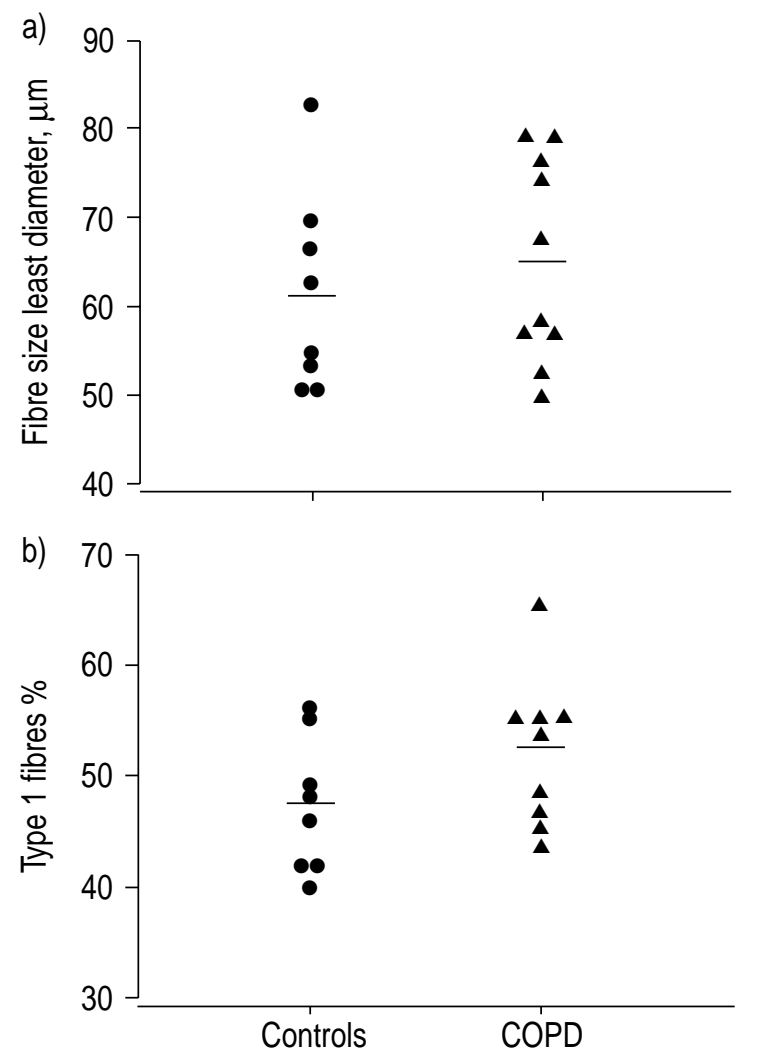

Fig. 1.-Comparisons among different subgroups for: a) fibre size; and b) the percentage of type I fibres. Controls are represented by circles whereas chronic obstructive pulmonary disease (COPD) patients are represented by triangles. Bars represent mean values. No significant statistical difference was observed for either comparison. 

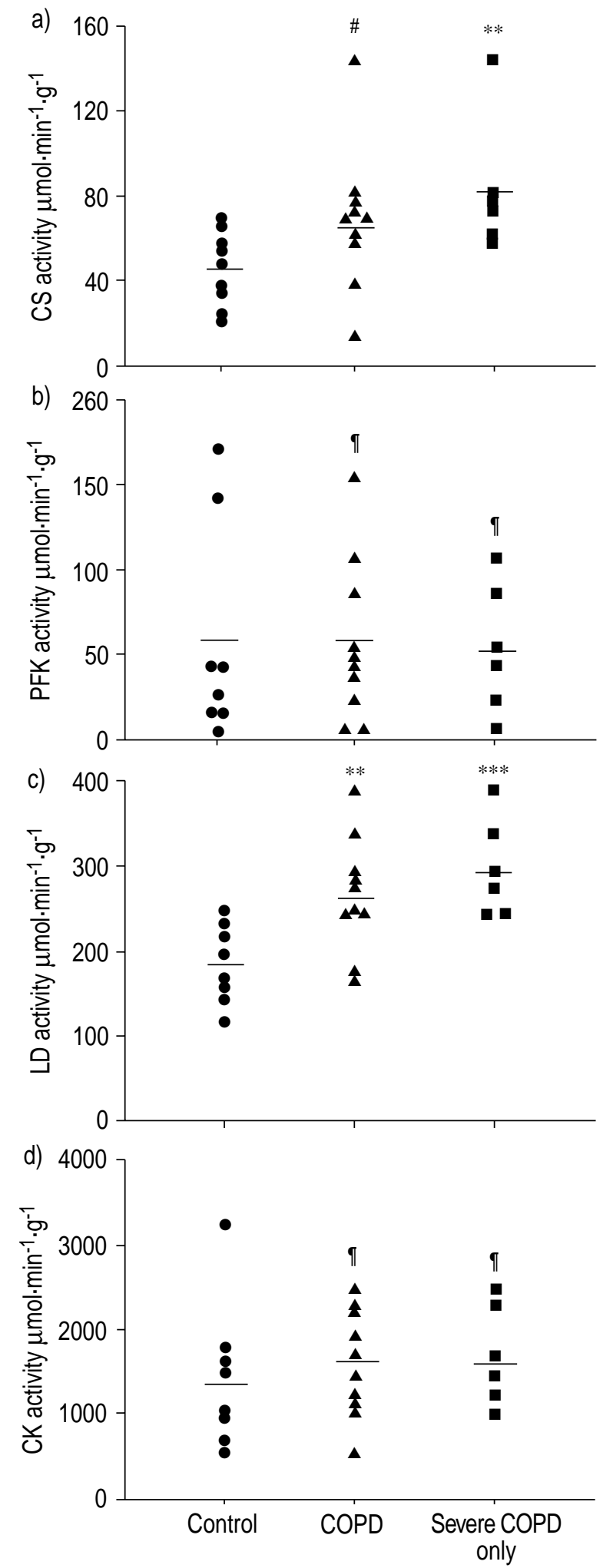

Fig. 2.-Comparisons among different subgroups (control, chronic obstructive pulmonary disease (COPD) and severe COPD) for enzyme activities. a) CS (citrate synthase) activity; b) PFK (phosphofructokinase) activity; c) LD (lactate dehydrogenase) activity; and d) CK (creatinine kinase) activity. Bars represent mean

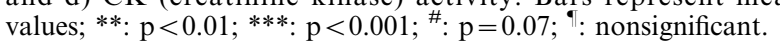

with $\mathrm{RV} / \mathrm{TLC}, \mathrm{r}=0.590, \mathrm{p}=0.01$ ), although this did not achieve statistical significance when only COPD patients were considered. Finally, the capacity for using energy stored in phosphocreatine, represented by the CK activity, was directly related to static lung volumes (with functional residual capacity (FRC), $\mathrm{r}=0.569$ for all individuals, $\mathrm{p}<0.05 ; \mathrm{r}=0.615$ for COPD, $\mathrm{p}=0.05)$.

\section{Discussion}

The present results show that oxidative capacity appeared to be preserved or even increased in DM of COPD patients. In the same sense, CK activity was found to be greater in subjects with higher lung volumes. Finally, the increase observed in LD activity suggests a simultaneous improved capacity to oxidise lactate to pyruvate.

Peripheral muscle dysfunction is involved in exercise limitation in COPD patients [1-3]. This functional deterioration consists of the decrease in muscle strength and resistance [3, 14], along with impaired bioenergetics during exercise [15] and appears to be associated to different structural changes, such as reductions in fat-free mass, muscle cross-sectional area [16, 17], capillarity [18], percentages of oxidative fibres [18] and myosin heavy chain (MyHC) isoforms [19] and a reduced activity of different oxidative enzymes $[4,5]$. Many of these changes would lead to a lower muscle aerobic capacity and thus, a reduced functional efficiency. In turn, glycolytic capacity appears to remain, on the whole, preserved [4] in the peripheral muscles of COPD, although some authors have observed occasional decreases in the activity of PFK [5].

A point that is not totally clear is whether these changes are common and homogeneous for different muscle groups. The results of this study support the notion that the findings previously reported in the quadriceps muscle would be present only in some muscle groups, and could be different or even absent in other locations. This would explain the relative preservation of muscle function in the upper limbs $[2,3]$ of COPD patients, as well as the functional adaptation of their respiratory muscles to hyperinflation [20]. In addition, maintenance of some structural properties, such as percentages of oxidative fibres and MyHC isoforms have been previously observed in biceps brachi [21], another muscle of the upper limb.

Another point of interest has to do with the causes presumably involved in the changes observed in the peripheral muscles of COPD patients. These causes can be classified as either local or systemic. Deconditioning due to reduction in daily activities [18] appears to be the most important local factor. In addition, local inflammation together with imbalance in the redox system [22] have also been proposed. In turn, systemic factors would include malnutrition [16], treatment with systemic steroids [23], hypoxaemia and/or hypercapnia [24], lung inflammation and comorbidity. Many of these factors can coexist and interact in different ways.

An interesting element is that most of the preceding 


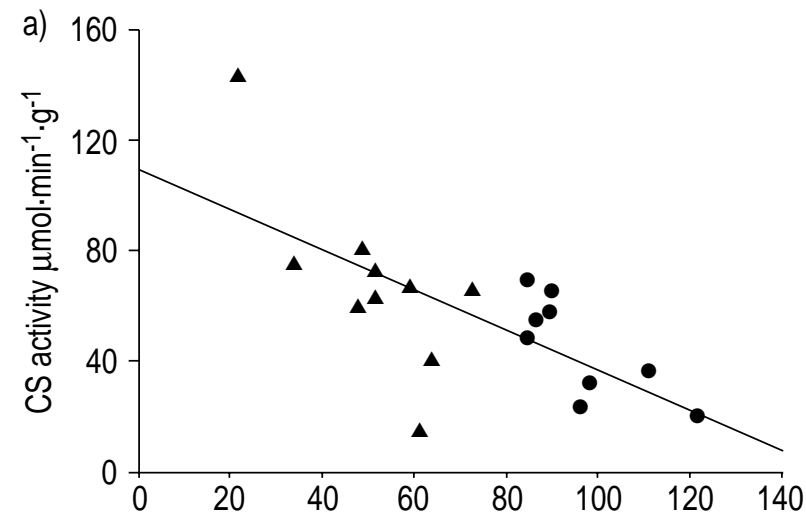

b)
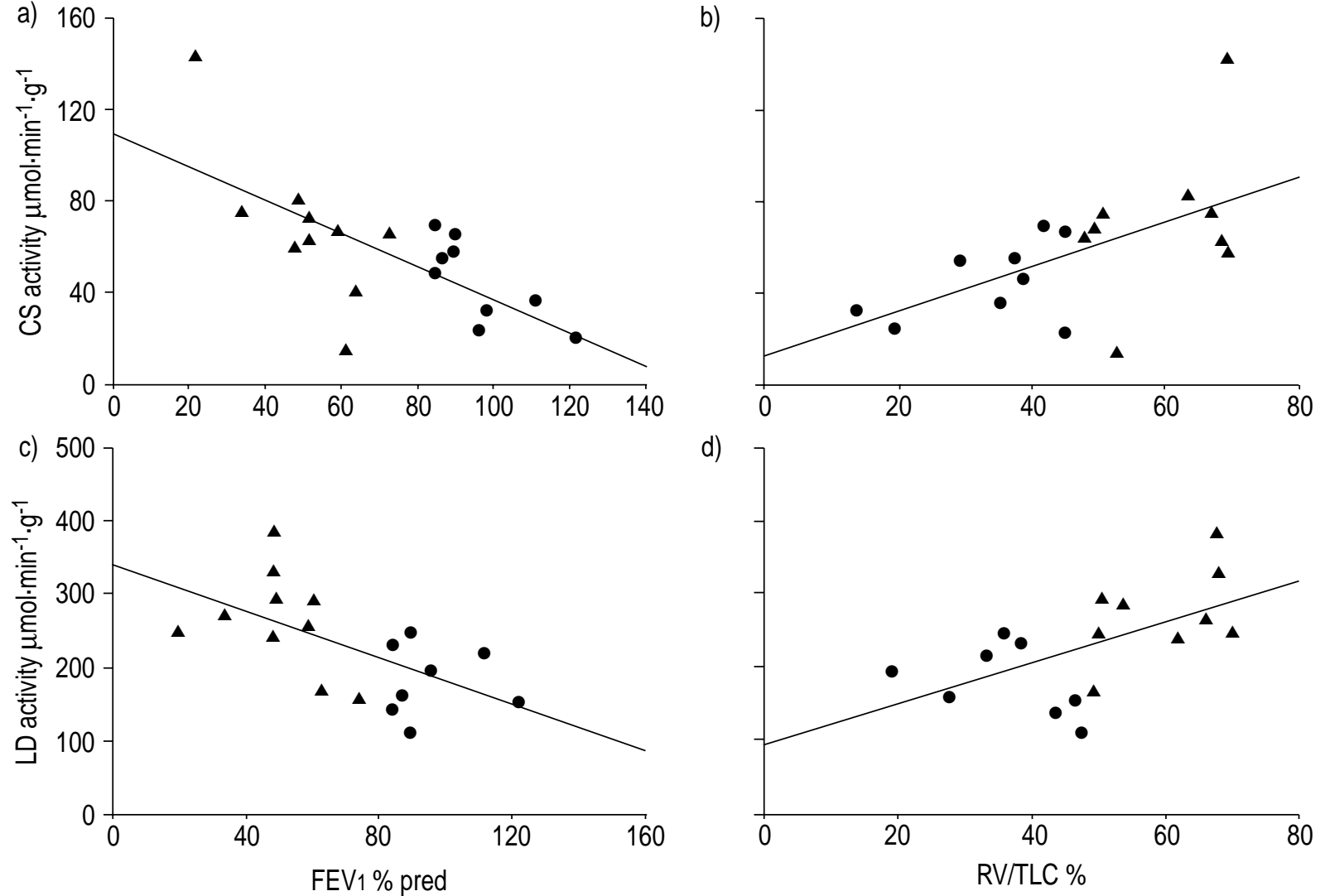

d)

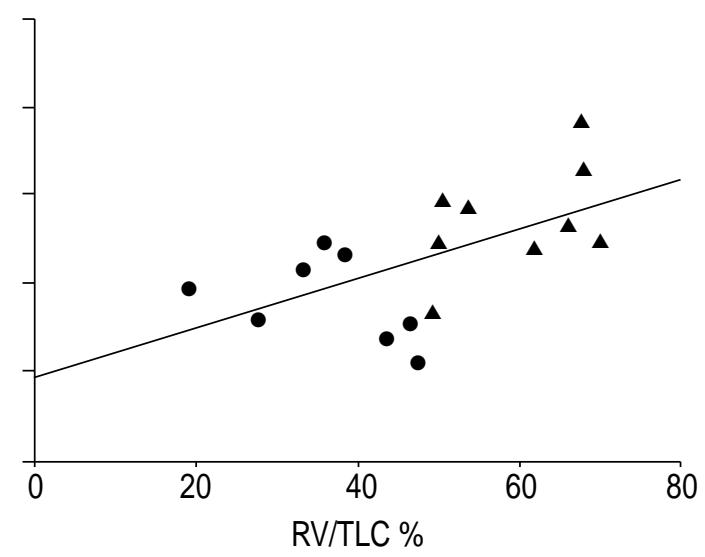

Fig. 3. - Relationships observed between: a) citrate synthase (CS) activity and forced expiratory volume in one second $(\mathrm{FEV} 1)(\mathrm{r}=-0.664$, $\mathrm{p}<0.01)$; b) CS activity and residual volume to total lung capacity ratio (RV/TLC) $(\mathrm{r}=0.563, \mathrm{p}=0.01)$; $\mathrm{c})$ lactate dehydrogenase (LD) activity and FEV1 $(r=-0.593, p<0.01)$; and d) LD activity and RV/TLC $(r=0.590, p=0.01)$. Circles represent control subjects whereas triangles are used for chronic obstructive pulmonary disease (COPD) patients.

studies have been performed in muscles of the lower limbs, mainly the vastus lateralis $[4,15,18,25]$. This approach is probably logical as these muscles are directly involved in the exercise capacity. However, different local and systemic causes can be simultaneously present in this location, acting in different qualitative and quantitative ways than in other muscle territories. The study of other muscle groups, such as respiratory muscles or those situated in the upper limbs, can contribute in clarifying the relative role played by some of these factors in each location. In this regard, this study's results suggest that local factors, such as the level and type of activity of a specific muscle group, play a key role in determining its final structure and metabolic characteristics.

The DM, the muscle chosen for this study, is located in the shoulder area and is a postural muscle in healthy individuals. It is responsible for arm elevation and abduction, as well as fixation of the shoulder joint. As with many other muscles in the upper limbs, DM does not directly participate in activities such as walking or running. For this reason, $\mathrm{DM}$ is not usually considered relevant in exercise limitation. Interestingly, this muscle is involved in activities such as the isometric contraction of the hand [26], which can be easily tested in a clinical laboratory (handgrip test).

As a whole, the present findings can be classified into two groups. On one hand, those which can be considered adaptive and are substantially different from those previously reported in the quadriceps muscle. The trend towards a greater CS activity observed in the DMs of this study's COPD patients (significant for severe COPD) can be included in this group, and can well be explained by both the maintenance of an appropriate level of daily muscle activity and/or the recruitment of the muscle under increased respiratory loads. In this regard, the authors have recently demonstrated that DM is progressively recruited by severe COPD patients breathing against incremental loads [27]. Similar results have been observed in the DM from paraplegic patients who use their upper limbs to increase their mobility [28].

In turn, although no changes were observed in the CK activity of the COPD patients as a group, those subjects with higher lung volumes showed greater activity for this enzyme. Briefly, CK is the enzyme involved in the use of energy stored as phosphocreatine, and its increase would allow for sufficient metabolic reserve to cope with increased energy demands (i.e. during exercise or exacerbations). Interestingly, the $\mathrm{CK}$ activity has been previously observed to be increased in skeletal muscles after endurance training [29].

The activity of PFK was preserved in the DM of COPD. This finding is similar to that previously 
observed in the quadriceps muscle [4] and is probably related to the weak influence of the level of activity in the regulation of this enzyme.

Lastly, the increase in the activity of LD, an enzyme acting in the anaerobic part of the glycolysis, could reflect other mechanisms. The LD activity appears to be modulated by the level of activity as well as by chronic hypoxia. Endurance training and exercise appear to result in a decrease in LD capacity, whereas power training induces the opposite phenomenon [13]. As far as COPD is concerned, an increase in the activity of this enzyme was observed in the quadriceps muscle of patients with severe airways obstruction and chronic hypoxia [5] but not in those with normal $\mathrm{Pa}, \mathrm{O}_{2}$ [4]. One hypothesis for the changes observed in the present study is that the LD induction would be related to repeated deteriorations in pulmonary gas exchange during exacerbations or exercise. Whatever the cause may be, the increase in LD activity suggests that the muscle would have an enhanced capacity to oxidise lactate to pyruvate, which can then be used in the tricarboxylic acid cycle. Alternatively, the increase in LD capacity would allow the muscle to improve the use of the anaerobic pathway when necessary.

\section{Limitations of the study}

A potential limitation of the present and former studies is the relatively small number of enzymes tested, and their "arbitrary" selection. However, this is inherent to the design: the number of enzymes is limited by the size of the samples, which in turn is subject to ethical factors. The selection was carried out on the basis of the role played by each enzyme in the main pathways.

Another possible criticism is the inclusion of only one skeletal muscle from each individual. In fact, a control group was used rather than a control muscle design. Reasons for this were ethical, as this was the authors' first study using an open muscle biopsy in outpatients suffering from COPD. In a more recent study, samples of both the vastus lateralis and DM were obtained from another group of COPD patients. Interestingly, structural changes appeared to be specific for each one of these muscles: fibres were smaller and type II were predominant in the vastus lateralis, whereas no changes in mean cross-sectional area and fibre relative percentages were observed in DM. However, and interestingly, fibres from this latter muscle evidenced a trimodal distribution, with normal as well as "atrophic" (smaller fibres) and "hypertrophic" (larger) subpopulations.

Finally, the use of handgrip to approximate the overall function of the upper limb muscles can also be criticized. The best option for specifically evaluating the strength of DM is to use dynamometry during isometric shoulder adduction. However, this technique has not been well standardized, shows bad reproducibility when testing patients and no reference values are currently accepted. The authors choose handgrip dynamometry, the simplest and most extended technique for assessing peripheral muscle function in the clinical setting, which, in addition, offers reference values.

In summary, the activity of the citrate synthase enzyme, an expression of the oxidative pathways, appears to be preserved and even increased in the deltoid muscle of chronic obstructive pulmonary disease patients. In the same way, subjects with higher lung volumes exhibited higher creatinine kinase activity. Finally, lactate dehydrogenase capacity was also increased in chronic obstructive pulmonary disease patients. These findings are different and can even be considered to move in the opposite direction to those previously observed in muscles from the lower limbs. This suggests that although systemic effects can not be excluded, local factors are essential in determining the phenotype of each skeletal muscle in patients suffering from chronic obstructive pulmonary disease.

\footnotetext{
Acknowledgements. Many thanks to N. Soler and A. Roig for their technical assistance at the Lung Function Laboratory and to J.A. Salazar for his editing aid.
}

\section{References}

1. Killian KJ, Leblanc P, Martin DH, Summers E, Jones NL, Campbell EJM. Exercise capacity and ventilatory, circulatory, and symptom limitation in patients with chronic airflow obstruction. Am Rev Respir Dis 1992; 146: 935-940.

2. Bernard S, LeBlanc P, Whittom F, et al. Peripheral muscle weakness in patients with chronic obstructive pulmonary disease. Am J Respir Crit Care Med 1998; 158: 629-634.

3. Gosselink R, Troosters T, Decramer M. Peripheral muscle weakness contributes to exercise limitation in COPD. Am J Respir Crit Care Med 1996; 153: 976980.

4. Maltais F, Simard AA, Simard C, Jobin J, Desgagnés $\mathrm{P}$, LeBlanc P. Oxidative capacity of the skeletal muscle and lactic acid kinetics during exercise in normal subjects and in patients with COPD. Am J Respir Crit Care Med 1996; 153: 288-293.

5. Jakobsson P, Jordfelt L, Henriksson J. Metabolic enzyme activity in the quadriceps femoris muscle in patients with severe chronic obstructive pulmonary disease. Am J Respir Crit Care Med 1995; 151: 374 377.

6. Roca J, Sanchís J, Agustí-Vidal A, et al. Spirometric reference values for a mediterranean population. Bull Eur Physiopathol Respir 1986; 22: 217-224.

7. Roca J, Burgos F, Barbera JB, et al. Prediction equations for plethysmographic lung volumes. Respir Med 1998; 92: 454-460.

8. Roca J, Segarra F, Rodríguez-Roisin R, Agustí-Vidal A. Static lung volumes and single-breath diffusing capacity reference values for a latin population. Am Rev Respir Dis 1990; 141: 1026-1032.

9. Wilson DO, Cooke NT, Edwards RHT, Spiro SG. Predicted normal values for maximal respiratory pressures in caucasian adults and children. Thorax 1984; 39: 535-538.

10. Mathiowetz V, Dove M, Kashman N, Rogers S. Grip 
and pinch strength: normative data for adults. Arch Phys Med Rehabil 1985; 66: 69-72.

11. Zammit VA, Newsholme EA. The maximum activities of hexokinase, phosphorylase, phosphofructokinase, glycerol phosphate dehydrogenase, lactate dehydrogenase, octopine dehydrogenase, phosphoenolpyruvate, carboxykinase, nucleoside diphosphatekinase, glutamate-oxalate transaminase and arginine kinase in relation of carbohydrate utilisation in muscle from invertebrates. Biochem J 1976; 160: 447-462.

12. Srere PA. Citrate synthase. Methods Enzymol 1969; 13: 3-11.

13. Tesch PA, Thorsson A, Gustavsson BE. Enzyme activities of FT and ST muscle fibers in heavy resistance trained athletes. J Appl Physiol 1989; 67: 83-87.

14. Serres I, Gautier V, Varray AL, Prefaut CG. Impaired skeletal muscle endurance related to physical inactivity and altered lung function in COPD. Chest 1998; 113: 900-905.

15. Sala E, Roca J, Marrades RM, et al. Effects of endurance training on skeletal muscle bioenergetics in chronic obstructive pulmonary disease. Am J Respir Crit Care Med 1999; 59: 1726-1734.

16. Engelen MAM, Schols AMWJ, Baken WC, Wesseling GJ, Wouters EFM. Nutritional depletion in relation to respiratory and peripheral skeletal muscle function in an outpatient population with chronic obstructive pulmonary disease. Eur Respir J 1994; 7: 1793-1797.

17. Wuyam B, Payen JF, Levy P, et al. Metabolism and aerobic capacity of skeletal muscle in chronic respiratory failure related to chronic obstructive pulmonary disease. Eur Respir J 1992; 5: 157-162.

18. Whittom F, Jobin J, Simard PM, et al. Histochemical and morphological characteristics of the vastus lateralis muscle in COPD patients. Med Sci Sports Exerc 1998; 30: 1467-1474.

19. Satta A, Migliori GB, Spanevello A, et al. Fibre types in skeletal muscles of chronic obstructive pulmonary disease patients related to respiratory function and exercise tolerance. Eur Respir J 1997; 10: 2853-2860.
20. Similowsky T, Yan S, Gaithier AP, Macklem PT. Contractile properties of the human diaphragm during chronic hyperinflation. N Engl J Med 1991; 325: 917923.

21. Sato Y, Asoh T, Honda Y, Fujimatso Y, Higuchi I, Oizumi K. Morphological and histochemical evaluation of biceps muscle in patients with chronic pulmonary emphysema manifesting generalized emaciation. Eur Neuro 1997; 37: 116-121.

22. Lawler JM, Powers SK. Oxidative stress, antioxidant status and the contracting diaphragm. Can J Appl Physiol 1998; 23: 23-55.

23. Decramer M, Lacquet LM, Fagard R, Rogiers P. Corticoisteroids contribute to muscle weakness in chronic airflow obstruction. Am Rev Respir Dis 1994; 150: 11-16.

24. Pastoris O, Dossena M, Foppa P, et al. Modifications by chronic intermittent hypoxia and drug treatment on skeletal muscle metabolism. Neurochem Res 1995; 20: $143-150$.

25. Sauleda J, García-Palmer F, Wiesner RJ, et al. Cytochrome oxidase activity and mitochondrial gene expression in skeletal muscle of patients with chronic obstructive pulmonary disease. Am J Respir Crit Care Med 1998; 157: 1413-1417.

26. Sporrong H, Palmerud G, Herberts P. Hand grip increases shoulder muscle activity. An EMG analysis with static hand contractions in 9 subjects. Acta Orthop Scand 1996; 67: 485-490.

27. Mendez R, Ramírez-Sarmiento A, Orozco-Levi M, Borrat X, Broquetas JM, Gea J. Evidence of deltoid muscle recruitment in COPD patients and the theory of muscle compartments. Am J Respir Crit Care Med 2000; 161 Suppl. A519.

28. Schantz P, Sjoberg B, Widebeck AM, Ekblom B. Skeletal muscle of trained and untrained paraplegics and tetraplegics. Acta Physiol Scand 1997; 161: 3139.

29. Apple FS, Rogers MA. Mitochondrial creatine kinase alterations in skeletal muscle during long-distance running. J Appl Physiol 1986; 61: 482-485. 